\title{
Traceability of Volatile Organic Compounds by Gas Chromatography-Mass Spectrometry and Its Reduction in Rubber Composites of Tire Inner Liner
}

\section{Xin Chen}

BUCT: Beijing University of Chemical Technology

\section{Boyu Zhang}

BUCT: Beijing University of Chemical Technology

Danling Wang

Zhong Ce Rubber Group Co., Ltd

\section{Li Chen}

Zhong Ce Rubber Group Co., Ltd

\section{Zhenxia Du}

BUCT: Beijing University of Chemical Technology

\section{Youping Wu ( $\nabla$ wuyp@mail.buct.edu.cn )}

Beijing University of Chemical Technology https://orcid.org/0000-0001-6723-7043

\section{Research Article}

Keywords: Volatile Organic Compounds (VOCs), Rubber Composites, Gas Chromatography-Mass Spectrometry (GC-MS), Traceability, Natural Rubber, Alkylphenol Resins

Posted Date: May 19th, 2021

DOl: https://doi.org/10.21203/rs.3.rs-429227/v1

License: (c) (1) This work is licensed under a Creative Commons Attribution 4.0 International License. Read Full License 


\section{Abstract}

Many parts of the vehicle cabin generate volatile organic compounds (VOCs) and they are hazardous to humans. In this study, VOCs in the inner liner of automobile spare tire, and separately the significant materials used in it, like raw rubber and resins, were detected by gas chromatography-mass spectrometry (GC-MS) coupled with extracting method of static headspace sampling (SHS). By comparison, the sources of VOCs can be traced back to raw rubbers and resins. And the results indicated that alkylphenol resins are the most volatile raw materials, which would release 2,4,4-trimethyl-1-pentene, and 2,2,4,6,6pentamethyl-3-heptene. Secondly, chlorobutyl rubber (CIIR) contained 3-methyl-pentane and methylcyclopentane. At the same time, through replacements of raw materials in initial formulation, such as alkylphenol resins and natural rubber (NR) with low VOCs, the total volatile organic compounds (TVOCs) discharged in inner liner could be reduced. We expected that the information gained from this work could provide references and positive significance for the manufacture of environmental-friendly tire products.

\section{Introduction}

Automobiles play an important role in modern lives, and people to stay in the cabin of it for a long time in daily life. VOCs emanate from some parts such as seals, seats, and spare tires, which will full fill the whole carriage. After a long time of direct contact, it will threaten the health of the human body, such as irritating the skin and increasing the risk of suffering cancer especially (Lim et al. 2014; Ramadan et al. 2018). When it was volatilized into the atmosphere, it will also harm the environment, such as enhancing atmospheric oxidation and forming the secondary organic aerosol (SOA) (Han et al. 2017; Nan et al. 2018). Therefore, VOCs in vehicles have received widespread attention. However, previous reports focused more on what substances are present in the car or what substances are emitted from the parts in automobiles (Faber et al. 2013; Geiss et al. 2009; Yue et al. 2017), the initial sources of these substances have required a significant effort to be explored.

To a large extent, some of the components listed above are prepared from rubber composites, which mainly consisted different kinds of raw rubbers and additives and produced under complex reaction conditions (Strangl et al. 2018). Earlier reports indicated that lots of VOCs were discovered in raw rubbers and additives. Many reports have studied rubbers, especially for NR. Idris (2012) emphasized the contribution of low molecular weight volatile fatty acids (VFA), such as acetic acid, and propionic acid to the malodorous gases emitted into the air during the drying stage of rubber processing. Chen et al (2002) detected the pyrolytic components of $\mathrm{NR}$, and the compounds are hydrocarbons $\left(\mathrm{C}_{2}\right.$ and $\left.\mathrm{C}_{3}\right)$, olefins (isoprene, limonene), and benzenes (benzene, toluene, xylene). Hoven (2003) examined the volatile compounds of different grades of rubber by GC-MS, which were classified according to their polarity as low-polar (aliphatic and aromatic hydrocarbons), medium-polar (aldehydes and ketones), and high-polar (volatile fatty acids and derivatives containing nitrogen or sulfur). Juntarachat et al. (2013) has tested two grades of rubber and pointed out that the enzymes and microorganisms, as well as thermal degradation, played an important role in the production of VOCs, and the short-chain fatty acids were odor-causing substance. Kamarulzaman et al. $(2019$, a) evaluated VOCs in NR using different techniques, 
and the results showed that the temperature will greatly influence the volatilities of VOCs and the highest detected compounds were aromatics and acids, and another study of them has focused more on the effects of several volatile substances on the specific smells of NR, such like volatile fatty acids (VFAs), esters, phenols, etc. (Kamarulzaman et al.,2019,b). In terms of relevant additives, such as antioxidants, plasticizers, tackifier resins, etc. (Agostini et al. 2010; Kikuchi and Ohtake 2006; Mess et al. 2011), various VOCs would emerge from them during the complicated processing condition and then emit into the atmosphere. These studies indicated that a broad range of VOCs with different functional groups were presented in rubbers composites. Therefore, it is feasible to trace the source of VOCs in the final products from the initial raw materials and reduce the volatilization of VOCs into the atmosphere.

For transferring VOCs from the sample into the detecting instrument, it was often required a pre-treatment process before detection and analysis. At present, the ideal extracting method is SHS, which is heating the material in the headspace bottle to evaporate the volatile substances. The advantages of SHS are simplicity, rapidity, and especially actuality, but the compounds present at low concentrations may not be identified (Cavalli et al. 2003; Jeleń and Gracka 2017; Soria et al. 2015). As for the qualitative and quantitative analysis of VOCs, GC-MS has widely used thanks to the advantages of simplicity and effectiveness in separating different components in mixtures (Al-Rubaye et al. 2017; Tang et al. 2020).

In this study, we aimed to evaluate the VOCs in the inner liner of spare tires, as it may potentially release VOCs during the storage process. The studies are as follows: (i) the inner liner of spare tires and the corresponding key raw materials in it were both analyzed by SHS-GC-MS; (ii) by comparing the results, the sources of partial VOCs could be elucidated; (iii) through formulation optimization using raw materials with low VOCs, the inner liner with low volatile could be obtained. We anticipate that the information gained from this work could provide references and positive significance for the manufacture of "green and environmental-friendly" tire products with low VOCs emissions.

\section{Experimental}

\subsection{Materials and Reagents}

Natural rubber (SPR 10\#) was obtained from the Philippines. Natural rubber (SVR 3L) was purchased from XiaoHong Co., Ltd. (Shanghai, China). Chlorinated butyl rubber (CIIR 1066) was provided by Exxon Mobil Co., Ltd. (America). Chlorinated butyl rubber (CIIR 1301) was provided by Xin Hui synthesis Co., Ltd. (Zhejiang, China). Carbon black N660 was obtained from Cabot Co., Ltd. (America). Stearic acid (SA) was purchased by Bai Li Co., Ltd. (Guangdong, China). Environment-friendly oil was purchased by Han Sheng Chemical Co., Ltd. (Ningbo, China). Antioxidant Poly(1,2-dihydro-2,2,4-trimethylquinoline) (RD) was purchased from Ke Li Co., Ltd, (Tianjin, China). Alkylphenol resin SL1801 and T5600 were all purchased from Hua Qi Co., Ltd. (Jiangsu, China). Accelerator 2,2'-Dithiobis(benzothiazole) (DM) was purchased from Shang Shun Co., Ltd. (Shandong, China). Zinc oxide (ZnO) was purchased from Jiaxing Beihua Co., Ltd. (Zhejiang, China). The other materials were all commercially available industrial products. The formulations and corresponding mass $(\mathrm{g})$ of the inner liner was shown in Table 1. 
Table 1

The formulation of the tire inner liner rubber composites (sample 1 \#)

\begin{tabular}{|ll|}
\hline Materials & Mass (g) \\
\hline NR SPR 10\# & 13 \\
\hline Alkylphenol resin SL1801 & 5 \\
\hline CIIR 1066 & 58 \\
\hline CIIR 1301 & 29 \\
\hline RD & 2 \\
\hline SA & 1 \\
\hline ZnO & 3 \\
\hline DM & 1 \\
\hline Sulfur & 1 \\
\hline Environment-friendly oil & 19 \\
\hline Carbon black N660 & 58 \\
\hline Total & 191 \\
\hline
\end{tabular}

\subsection{Preparation of rubber materials}

First, raw rubbers and additives are shown in Table 1 were mixed homogeneously by a two-roll mill (X(S)K-160, Shanghai rubber machinery Co., Ltd., China) at room temperature to obtain the rubber compound. Then the moving die rheometer (MR-C3, RADE instrument Co., Ltd., Beijing, China) was performed to determine the optimal vulcanization time $\left(t_{90}\right)$, and lastly, the compound was vulcanized on a platen press vulcanizer (LB-D350×350, Dong Fang Machinery Co., Ltd., Huzhou, China) under the pressure of $15 \mathrm{MPa}$ at $151^{\circ} \mathrm{C}$ for $35 \mathrm{~min}$, which was named as 1 \# (Dimensions: $13 \mathrm{~mm} \times 11 \mathrm{~mm} \times 2$ $\mathrm{mm})$.

\subsection{Sample pre-treatment}

The sample 1 \# was cut into small pieces $(2 \mathrm{~mm} \times 2 \mathrm{~mm} \times 2 \mathrm{~mm}$ ), and then stored in a sealed bag for further detection. Similarly, raw materials listed in Table 1 including NR SPR10\#, CIIR1066, CIIR1301, alkylphenol resin SL1801, were also collected and stored in the same way, and the results were shown in the Supplementary Materials.

\subsection{VOCs analysis}

An Agilent gas chromatograph (TRACE 1300 series) equipped with a DB-WAX analytical fused-silica column $(30 \mathrm{~m} \times 0.25 \mathrm{~mm} \times 0.25 \mu \mathrm{m})$ was used. Compounds were injected into the TriPlus RSH 
autosampler by a programmable temperature vapourising (PTV) injector. All GC-MS system components were supplied by Thermo Fisher Scientific Co., Ltd. (USA).

SHS-GC ramp conditions were as follows: the initial oven temperature was set at $50{ }^{\circ} \mathrm{C}$ and held for 4 min, then raised to $250^{\circ} \mathrm{C}$ at $15^{\circ} \mathrm{C} / \mathrm{min}$, and then held for $5 \mathrm{~min}$, the split ratio is $10: 1$. The temperatures of the MS detector transfer line and ionization source were set as $230{ }^{\circ} \mathrm{C}$ and $250{ }^{\circ} \mathrm{C}$, respectively. Helium (high purity, 99.999\%) was used as the carrier gas at a flow rate of $1 \mathrm{~mL} / \mathrm{min}$. Electron Impact (El) was used as an ionization source at $70 \mathrm{eV}$. Detector voltage was $1700 \mathrm{~V}$ and detection was carried out in full scan acquisition covering a mass range $(\mathrm{m} / \mathrm{z})$ of 33-400 amu. After comparison with the NIST14, the probability of the identified substances was higher than $80 \%$.

\section{Results And Discussion}

\subsection{Identification of VOCs Compounds}

The total ion chromatogram-mass spectrometry (TIC-MS) of the sample $1 \#$ is shown in Fig. 1, and the corresponding detected compounds have been summarized in Table 2. A total of 20 compounds could be identified, and from the point of view of chemical composition, these substances could be categorized based on different functional groups, such as alkanes, ketones, alkenes, alcohols, phenols, quinolines. Meanwhile, these 20 substances were compared with the results of raw materials (Supplementary Information (SI): Table 4: NR SPR 10\#, Table 6: CIIR 1066, Table 7: CIIR 1301, and Table 8: resin SL1801) for traceability. 
Table 2

The identified compounds detected from the sample 1\#

\section{Retention time/min Abundance Substance}

\section{Num.}

$\left(\times 10^{7}\right)$

(1)

1

$1 \quad 1.4$

2

1.50

126

carbon dioxide

$-78$

3

4

5

6

8

8

9

11

12

$13 \quad 9.24$

14

159.50

56.6

3-methyl-pentane

64

19.7

methyl-cyclopentane

72

128

2,4,4-trimethyl-1-pentene

101

10.2

acetone

56

3.1

2-methyl-2-propanol

83

$7 \quad 3.26$

6.2

ethanol

78

$8 \quad 4.87$

3.9

octamethylcyclotetrasiloxane

175

$\begin{array}{lll}9 & 6.52 & 7.7\end{array}$

$10 \quad 6.72$

3.9

2-nonen-4-one

201

$11 \quad 7.25$

5.3

1-methoxy-2-propanol

118

8.97

11.1

4,4-dimethyl-heptane

135

2,2,4,6,6-pentamethyl-3-heptene

180

7.5

2,2,4,6,6-pentamethyl-3-heptene

180

2.7

(z)-5,5-dimethyl-2-hexene

120

$\begin{array}{lll}16 & 12.53 & 3.2\end{array}$

\begin{tabular}{|ll}
17 & 14.29 \\
18 & 14.75
\end{tabular}

$\begin{array}{lll}18 & 14.75 & 0.2 \\ 19 & 14.99 & 4.9\end{array}$

20

20

15.84

1

butylated hydroxytoluene

365

0.2

benzothiazole

231

4.9

phenol

182

3.8

1,2-dihydro-2,2,4-trimethylquinoline

293

Except for the peak of air (carbon dioxide, $1.44 \mathrm{~min}$ ), 2,4,4-trimethyl-1-pentene (1.84 $\mathrm{min}$ ) was the most abundant substance. It was often used as organic synthesis intermediates for the production of octylphenol and nonylphenol (Chaudhuri and Sharma 1991). And it was observed in an appreciable quantity in resin SL1801 (Table 8). Therefore, it could be deduced that the source of 2,4,4-trimethyl-1pentene was the alkylphenol resin SL1801. Similarly, 2,2,4,6,6-pentamethyl-3-heptene (8.97 min) were also detected in the resin SL1801 (Table 8). This may be introduced by the thermal decomposition of resin during processing, as the reaction scheme shown in Fig. 2 (a) (Fisher 2010). The side group will 
break off during the reaction and produce 2,2,4,6,6-pentamethyl-3-heptene. Besides, alkylphenol resin is easy to decompose at high temperatures resulting in the emergence of numerous small molecules, as seen in Table 8. These substances will inevitably be remained in the sample and could be detected when the material is prepared. However, other substances are more diverse, such as 2-nonen-4-one (6.52 min), (z)-5,5-dimethyl-2-hexene (9.37 $\mathrm{min})$, 4-tert-butylcyclohexanone (9.50 $\mathrm{min})$, etc., but their reaction pathway is not yet definite.

3-methyl-1-pentane (1.50 $\mathrm{min})$ and methyl-cyclopentane $(1.65 \mathrm{~min})$ were also owed a high abundance in the results. As seen from Table 6 and Table 7, they were all found in the two types of chlorobutyl rubber (CIIR 1066 and 1301), which may be produced during the preparation of CIIR, as the requirement of using positively constructed alkane solvents to dissolve butyl rubber (Newman et al. 1981).

Butylated hydroxytoluene (BHT, $14.29 \mathrm{~min}$ ), a white crystalline substance, was widely used in foods, rubber, and petroleum products (Yehye et al. 2015). Previous research has also reported that it is a potential pyrolysis product of sinapic acid in NR (Juntarachat et al. 2013). But the results of Table 6 indicated that it is more likely to be added directly to CIIR as an antioxidant (Babich 1982).

Benzothiazole ( $8.97 \mathrm{~min}$ ) was a heterocyclic compound, which is often used in various products, previous studies have reported that it has been detected in NR (Hoven et al. 2003). In the rubber industry, it was used as vulcanization accelerating additives in rubber (Chung et al. 2011). In terms of structure, the decomposition of the accelerator DM is more suitable to explain the presence of benzothiazole, as shown in Fig. 2 (b).

Phenol (14.75 min), a colorless needle-like crystal with a characteristic odor. It comes from NR SPR10\# and resin SL1801, as in line with the results of Table 4 and Table 8, respectively. In NR, it might result from the thermal degradation of lignin and fatty acid esters or microbial degradation of aromatic amino acids (Zhang et al. 2020) and in terms of resin SL180, it might stem from the decomposition products of the resin as the reaction scheme depicted in Fig. 2 (a).

From the perspective of structural similarity, it is believed that the 1,2-dihydro-2,2,4-trimethylquinoline is emerged by the decomposition of the antioxidant RD as shown in Fig. 2 (c). The antioxidant RD is a common additive that could provide better protection for rubber to resist thermal and oxidative aging.

Above all, among these detected substances, as the corresponding boiling points listed in Table 2, smaller molecular weight compounds with boiling points ranging from 56 to $200^{\circ} \mathrm{C}$ appear to be the domination, while some substances with higher boiling points like 1,2-dihydro-2,2,4-trimethylquinoline would also coexist. However, due to complex reactions, although some substances are associated with raw materials, the reaction pathways are not be figured out yet.

\subsection{Comparison of VOCs in resin and NR}

Based on the above results, it makes sense to reduce the generation of VOCs by formulation adjustments. Therefore, NR and alkylphenol resin with more volatile substances were replaced by raw materials NR 
SVR 3L and resin T5600 to reduce the volatilization of VOCs. The test method is similar to the descriptions mentioned above, and the testing results of NR SVR 3L and alkylphenol resin T5600 are listed in Table 5 and Table 9, respectively.

Figure 3 shows the comparison of the abundance of NR SPR 10\# and NR SVR 3L. Both types of NR mainly contain VFA and aldehydes with low molecular weight such as butyraldehyde, valeraldehyde isobutyraldehyde, and isovaleraldehyde. But it demonstrated that the abundance of TVOCs in SPR 10\# was higher than that in SVR 3L. This difference was caused by the different production methods (coagulation process, drying process) and storage time in rubbers (Juntarachat et al. 2013). For example, SVR $3 L$ is prepared from natural latex through filtration and coagulation processes, then drying and packing. SPR 10\# is prepared from miscellaneous rubber containing sand and dust, which makes the NR SPR 10\# have been oxidized and many impurities. The worse the grade of rubber, the more volatile substances (Hoven et al. 2003, Sakdapipanich and Insom 2006). It suggested that SVR $3 L$ is more suitable to manufacture products with lower VOCs.

The use of tackifier resin in synthetic elastomers was for achieving the desired level of tackiness in a rubber compound (Lattimer et al. 1989). Figure 4 shows the comparison of the abundance of VOCs in resin SL1801 and resin T5600, especially for 2,4,4-trimethyl-1-pentene, 2,2,4,6,6-pentamethyl-3-heptene, due to their significant contribution to the volatilization of TVOCs in the inner liner. It can be seen that resin T5600 has a lower abundance of VOCs, which also indicated that T5600 resin was more conducive to the manufacture of products with lower VOCs.

\subsection{VOCs via formulation adjustments}

The above analysis resulted in the following formulation improvements as shown in Table 3. Firstly, based on the initial formulation 1\#, NR SPR 10\# was replaced by the NR SVR3L and was named as 2\#; then based on 2\#, the alkylphenol resin SL1801 was replaced by resin T5600, which were named as 3\#. It should be noted that the processing of materials, preparation of vulcanizates, sample pre-treatment, and VOCs analysis for $2 \#, 3 \#$ were kept as the same with $1 \#$. 
Table 3

The formulation and corresponding mass (g) after raw materials replacements

\begin{tabular}{|llll|}
\hline Materials & 1\# & 2\# & 3\# \\
\hline NR SPR 10\# & 13 & 0 & 0 \\
\hline NR SVR 3L & 0 & 13 & 13 \\
\hline resin SL1801 & 5 & 5 & 0 \\
\hline resin T5600 & 0 & 0 & 5 \\
\hline CIIR 1066 & 58 & 58 & 58 \\
\hline CIIR 1301 & 29 & 29 & 29 \\
\hline RD & 2 & 2 & 2 \\
\hline SA & 1 & 1 & 1 \\
\hline ZnO & 3 & 3 & 3 \\
\hline DM & 1 & 1 & 1 \\
\hline Sulfur & 1 & 1 & 1 \\
\hline Environment-friendly oil & 19 & 19 & 19 \\
\hline Carbon black N660 & 58 & 58 & 58 \\
\hline Total & 191 & 191 & 191 \\
\hline
\end{tabular}

Figure 5 shows the abundance of TVOCs after formulation changing according to Table 3 . After changing the brand of NR, it had a positive effect on the reduction of TVOCs. And as expected, after changing the different brand of alkylphenol resin in $3 \#$, the abundance of TVOCs continued to decrease and presented the lowest in the three samples. Compared with the initial sample 1\#, TVOCs in $3 \#$ have achieved a target reduction of $20 \%$. Above all, from the point of view of environmental protection, through the change of raw materials, TVOCs discharged in inner liner could be reduced.

\section{Conclusions}

In this study, applying gas chromatography-mass spectrometry (GC-MS) coupling with static headspace sampling (SHS), we have detected the VOCs in rubber composites of tire inner liner and tracing their sources back to the raw materials and additives, which may be released into the atmosphere during the usage of products.

(i) A total of 20 compounds have been identified, they belong to alkanes, ketones, alkenes, alcohols, phenols, quinolines. 
(ii) Through traceability, it was found that alkylphenol resin were the main volatile raw materials, it mainly contains 2,4,4-3-methyl-1-pentene and 2,2,4,6,6-pentamethyl-3-heptene. The second was CIIR, which contained 3-methyl-pentane, and methyl-cyclopentane. During the processing and reaction, additives like $\mathrm{DM}$ and RD will produce benzothiazole and 1,2-dihydro-2,2,4-trimethylquinoline, respectively.

(iii) Through change the brand of NR (SVR 3L) and alkylphenol resin (T5600), TVOCs discharged in the inner liner could be reduced $20 \%$.

In summary, this study has brought improvements in the knowledge of VOCs present in tire products and their raw materials, which could provide a reference for designing rubber composites of low VOCs emission for the tire industry.

\section{Declarations}

\section{Ethics approval and consent to participate}

Not applicable.

\section{Consent for publication}

Not applicable.

\section{Availability of data and materials}

The data sets supporting the results of this article are included within the article and its additional files.

\section{Competing interests}

The authors declare no competing interests.

\section{Funding}

This research did not receive specific funding.

\section{Authors' contributions}

All authors contributed to the conception and design of this study. The experiment and the manuscript first draft were performed by Xin Chen and Boyu Zhang. The literature search and data analysis were performed by Xin Chen. The formulation design was performed by Danling Wang, Li Chen, Xin Chen, and Boyu Zhang. The review and editing Youping Wu and Zhenxia Du. All authors commented on previous versions of the manuscript. All authors read and approved the final manuscript.

\section{Acknowledgment}

The authors would like to acknowledge Ph.D. Han Qingyuan for improving the English of this manuscript. 


\section{References}

1. Agostini M, Vocht FD, Tongeren MV, Cherrie JW, Galea KS, Kromhout H (2010) Exposure to rubber process dust and fume since 1970s in the United Kingdom; influence of origin of measurement data. JEM 12(5): 1170-1178. https://doi.org/10.1039/b923497g

2. Al-Rubaye AF, Hameed IH, Kadhim J (2017) A Review: Uses of Gas Chromatography-Mass Spectrometry (GC-MS) Technique for Analysis of Bioactive Natural Compounds of Some Plants. Int J Endocrinol 9(1): 81-85. https://doi.org/10.25258/ijtpr.v9i01.9042

3. Babich H (1982) Butylated hydroxytoluene (BHT): A review. Environ. Res 29(1): 1-29. https://doi.org/10.1016/0013-9351(82)90002-0

4. Cavalli JF, Fernandez X, Lizzani-Cuvelier L, Loiseau AM (2003) Comparison of static headspace, headspace solid phase microextraction, headspace sorptive extraction, and direct thermal desorption techniques on chemical composition of French olive oils. J Agric Food Chem 51(26): 7709-16. https://doi.org/10.1021/jf034834n

5. Chaudhuri B, Sharma MM (1991) Alkylation of phenol with a-methylstyrene, propylene, butenes, isoamylene, 1-octene, and diisobutylene: Heterogeneous vs homogeneous catalysts. Ind. Eng. Chem. Res 30(1): 227-231. https://doi.org/10.1021/ie00049a035

6. Chen F, Qian J (2002) Studies on the thermal degradation of cis-1, 4-polyisoprene. Fuel 81(16): 20712077. https://doi.org/10.1016/S0016-2361(02)00147-3

7. Chung $\mathrm{H}$, Choi A, Cho IH, Kim YS (2011) Changes in fatty acids and volatile components in mackerel by broiling. Eur J Lipid Sci Tech 113(12): 1481-1490. https://doi.org/10.1002/ejlt.201000510

8. Faber J, Brodzik K, Gołda-Kopek A, Łomankiewicz D (2013) Benzene, toluene and xylenes levels in new and used vehicles of the same model. J Environ Sci (China) 25(11): 2324-2330. https://doi.org/10.1016/S1001-0742(12)60333-7

9. Fisher JD (2010) Alkyl Phenol Resins in Adhesive and Rubber Applications. In: Pilato L. (eds) Phenolic Resins: A Century of Progress. Springer, Berlin, Heidelberg. https://doi.org/10.1007/978-3642-04714-5_17

10. Geiss O, Tirendi S, Barrero-Moreno J, Kotzias D (2009) Investigation of volatile organic compounds and phthalates present in the cabin air of used private cars. Environ Int 35(8): 1188-1195. https://doi.org/10.1016/j.envint.2009.07.016

11. Han D, Zhen W, Cheng J, Qian W, Wang H (2017) Volatile organic compounds (VOCs) during nonhaze and haze days in Shanghai: characterization and secondary organic aerosol (SOA) formation. Environ. Sci. Pollut. Res 24(4): 1-11. https://doi.org/10.1007/s11356-017-9433-3

12. Hoven VP, Rattanakaran K, Tanaka Y (2003) Determination of chemical components that cause malodor from natural rubber. Rubber Chem Technol 76(5): 1128-1144. https://doi.org/10.5254/1.3547792

13. Idris NF, Kamarulzaman NH, Nor ZM (2012) Determination of volatile fatty acids from raw natural rubber drying activity by thermal desorption-gas chromatography. Chem. Eng. J 30: 175-180. 
https://doi.org/10.3303/CET1230030

14. Jeleń H, Gracka A (2017) Static Headspace Extraction with Compounds Trapping for the Analysis of Volatile Lipid Oxidation Products. Food Anal Methods 10(8): 2729-2734. https://doi.org/10.1007/s12161-017-0838-x

15. Juntarachat N, Bouvier N, Lepoutre JP, Roland A, Sainte-Beuve J, Granet F, Salmon JM, Rigou P, Chalier P (2013) Identification by GC-O and GC-MS of new odorous compounds in natural rubber. J. Appl. Polym. Sci 130(3): 1863-1872. https://doi.org/10.1002/app.39356

16. Kamarulzaman NH, Le-Minh N, Fisher RM, Stuetz RM (2019) Quantification of VOCs and the development of odour wheels for rubber processing. Sci. Total Environ 657: 154-168. https://doi.org/10.1016/j.scitotenv.2018.11.451

17. Kamarulzaman NH, Le-Minh N, Stuetz RM (2019) Identification of VOCs from natural rubber by different headspace techniques coupled using GC-MS. TALANTA 191: 535-544. https://doi.org/10.1016/j.talanta.2018.09.019

18. Kikuchi T, Ohtake Y (2006) The Analysis of Additives in Rubber Products. J Rubber Res 79(6): 335. https://doi.org/10.2324/gomu.79.335

19. Lattimer RP, Kinsey RA, Layer RW, Rhee CK (1989) The Mechanism of Phenolic Resin Vulcanization of Unsaturated Elastomers. Rubber Chem Technol 62(1): 107-123. https://doi.org/10.5254/1.3536228

20. Lim S. K, Shin HS, Yoon KS et al (2014) Risk assessment of volatile organic compounds benzene, toluene, ethylbenzene, and xylene (BTEX) in consumer products. Toxicol Environ Health A 77(22-24): 1502-21. https://doi.org/10.1080/15287394.2014.955905

21. Mess A, Vietzke JP, Rapp C, Francke W (2011) Qualitative analysis of tackifier resins in pressure sensitive adhesives using direct analysis in real time time-of-flight mass spectrometry. Anal. Chem 83(19): 7323-7330. https://doi.org/10.1021/ac2011608

22. Nan J, Yin S, Yue G, Li J, Kang P, Zhang R, Tang X (2018) Characteristics of mass concentration, chemical composition, source apportionment of PM 2.5 and PM 10 and health risk assessment in the emerging megacity in China. Atmospheric Pollut. Res 9(2): 309-321. https://doi.org/10.1016/j.apr.2017.07.005

23. Newman NF, Roper R, West RK (1981) Continuous process for the preparation of bromochlorinated butyl rubber. https://www.freepatentsonline.com/4254240.html

24. Ramadan A, Yassin MF, Alshammari BZ (2018) Health Risk Assessment Associated with Volatile Organic Compounds in A Parking Garage. Int J Environ Sci Technol 16(6): 2549-2564. https://doi.org/10.1007/s13762-018-1641-y

25. Sakdapipanich J, Insom K (2006) High-resolution gas chromatography-mass spectrometry. Kautschuk und Gummi Kunststoffe 59(7/8): 382. https://doi.org/10.1017/S0033583500001244

26. Soria AC, García-Sarrió M, Sanz ML (2015) Volatile sampling by headspace techniques. Trends Analyt Chem 71: 85-99. https://doi.org/10.1016/j.trac.2015.04.015 
27. Strangl M, Schlummer M, Maeurer A, Buettner A (2018) Comparison of the odorant composition of post-consumer high-density polyethylene waste with corresponding recycled and virgin pellets by combined instrumental and sensory analysis. J. Clean. Prod 181: 599-607. https://doi.org/10.1016/j.jclepro.2018.01.137

28. Tang J, Ma S, Liu R, Yue C, Li G, Yu Y, Yang Y, An T (2020) The pollution profiles and human exposure risks of chlorinated and brominated PAHs in indoor dusts from e-waste dismantling workshops:

Comparison of GC-MS, GC-MS/MS and GC× GC-MS/MS determination methods. J Hazard Mater 394: 122573. https://doi.org/10.1016/j.jhazmat.2020.122573

29. Yehye WA, Rahman NA, Ariffın A, Abd Hamid SB, Alhadi AA, Kadir FA, Yaeghoobi M (2015) Understanding the chemistry behind the antioxidant activities of butylated hydroxytoluene (BHT): A review. Eur J Med Chem 101: 295-312. https://doi.org/10.1016/j.ejmech.2015.06.026

30. Yue T, Yue X, Chai F, Hu J, Lai Y, He L, Zhu R (2017) Characteristics of volatile organic compounds (VOCs) from the evaporative emissions of modern passenger cars. Atmospheric Environ 151: 62-69. https://doi.org/10.1016/j.atmosenv.2016.12.008

31. Zhang S, Xiao J, Wang G, Chen G (2020) Enzymatic hydrolysis of lignin by ligninolytic enzymes and analysis of the hydrolyzed lignin products. Bioresour. Technol 304(1): 122975. https://doi.org/10.1016/j.biortech.2020.122975

\section{Figures}

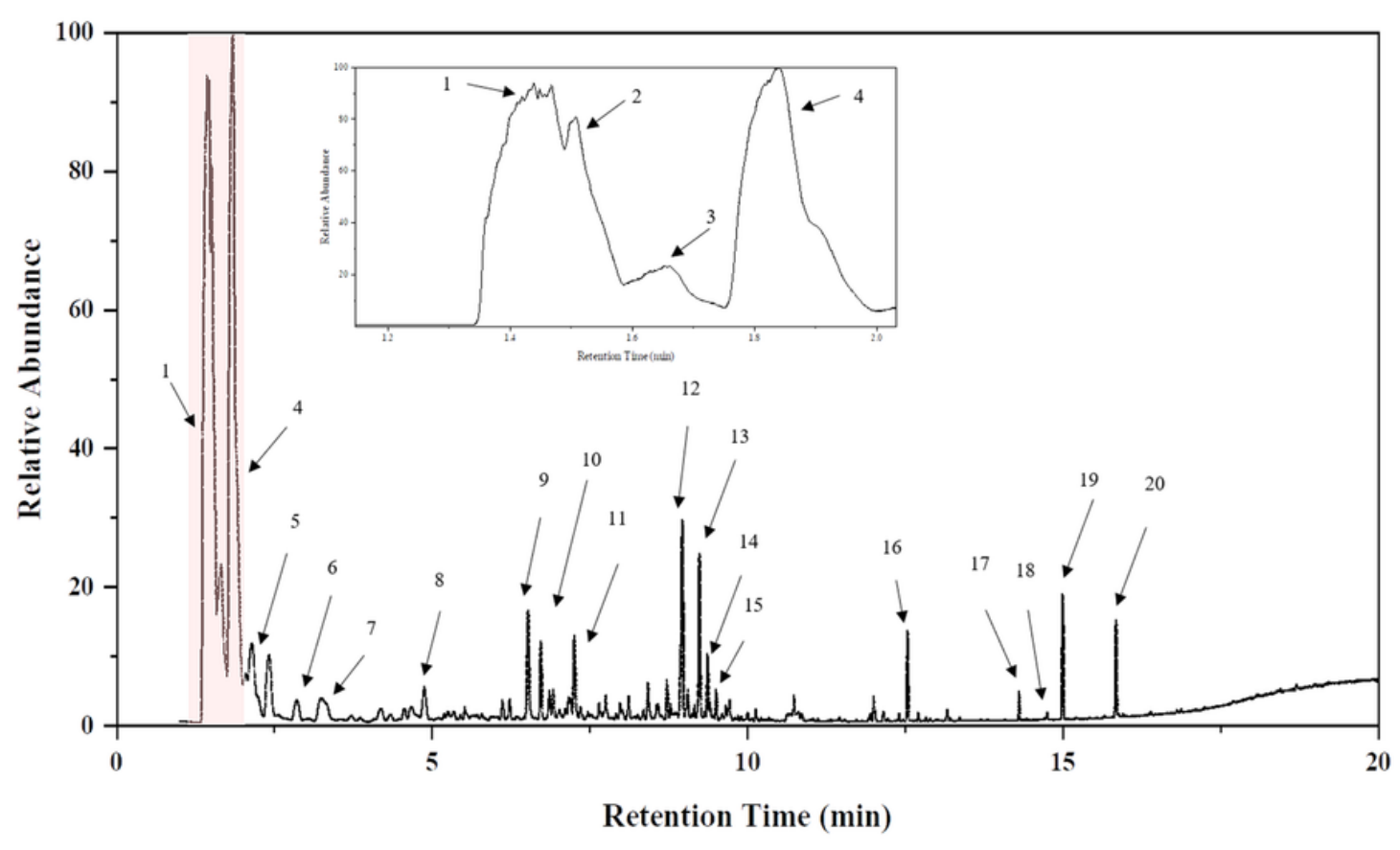

Figure 1 
The total ion chromatogram-mass spectrometry (TIC-MS) of sample 1 \#

(a)

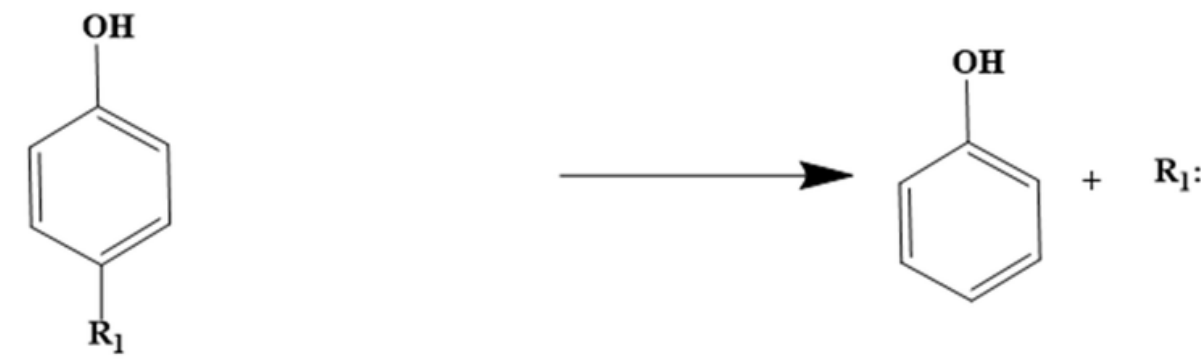

phenol

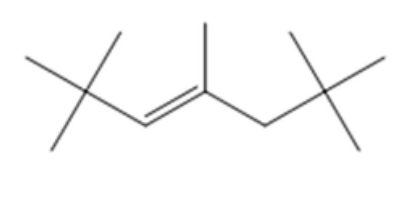

Alkylphenol Resins

(b)<smiles>c1ccc2sc(SSc3nc4ccccc4s3)nc2c1</smiles>

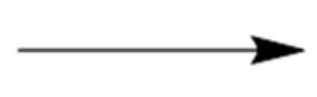

Accelerator DM

(c)

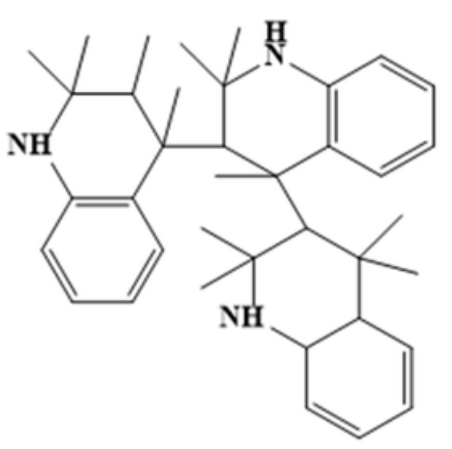

Antioxidant RD

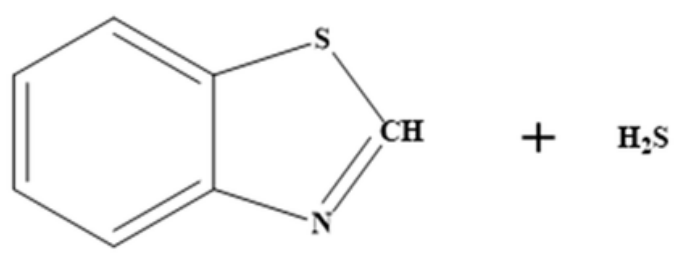

Benzothiazole sulfureted hydrogen

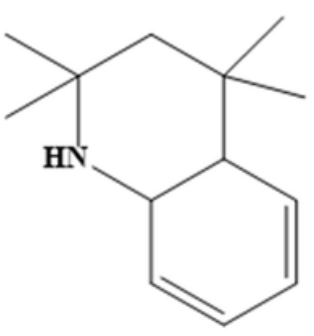

1,2-dihydro-2,2,4-trimethylquinoline

Figure 2

Possible pathways for the detected substances: (a) thermal decomposition of alkylphenol resin, (b) thermal decomposition of the accelerator $\mathrm{DM}$, (c) thermal decomposition of the antioxidant RD. 


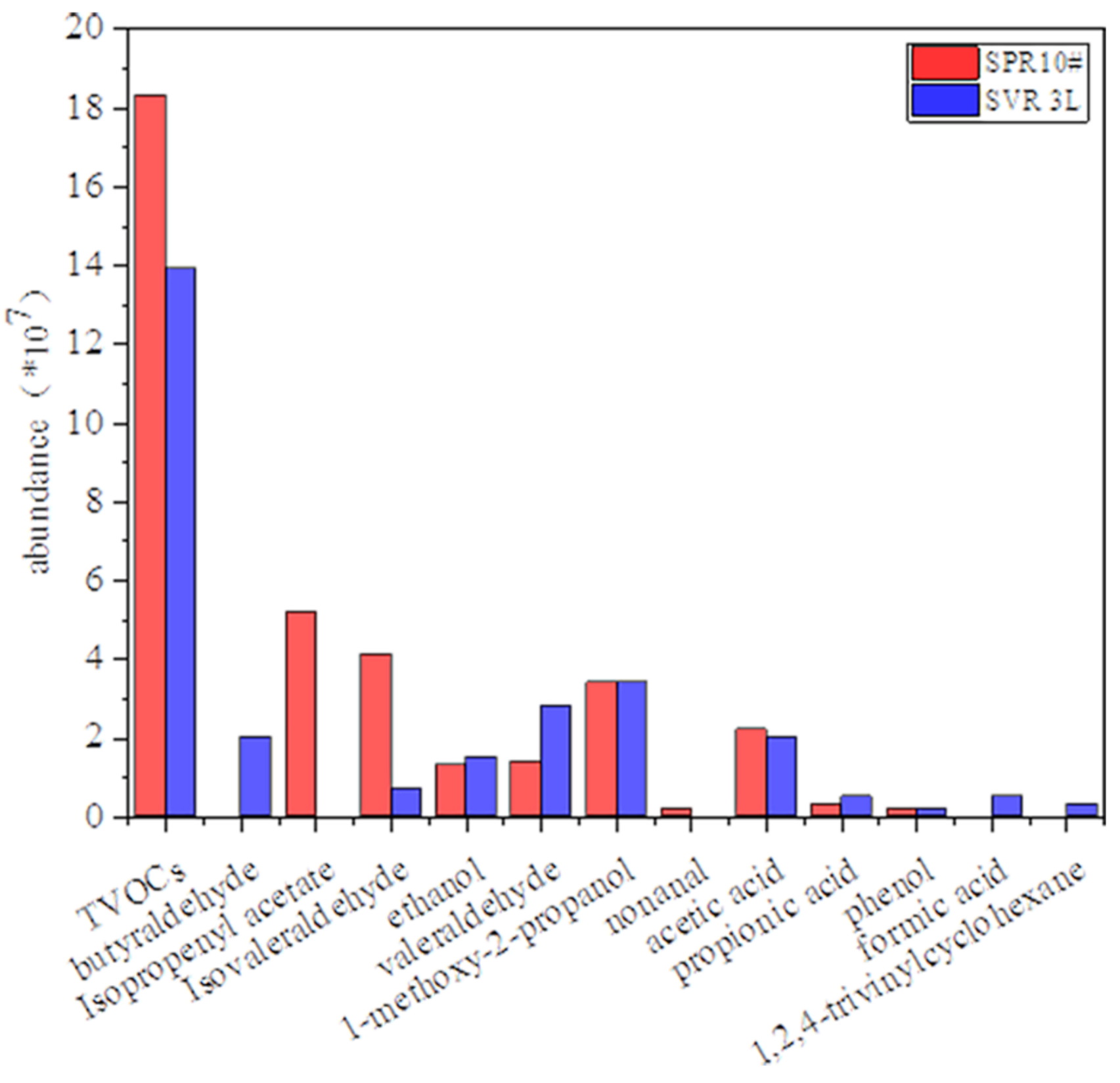

Figure 3

The abundance of VOCs in NR SPR 10\# and NR SVR 3L 


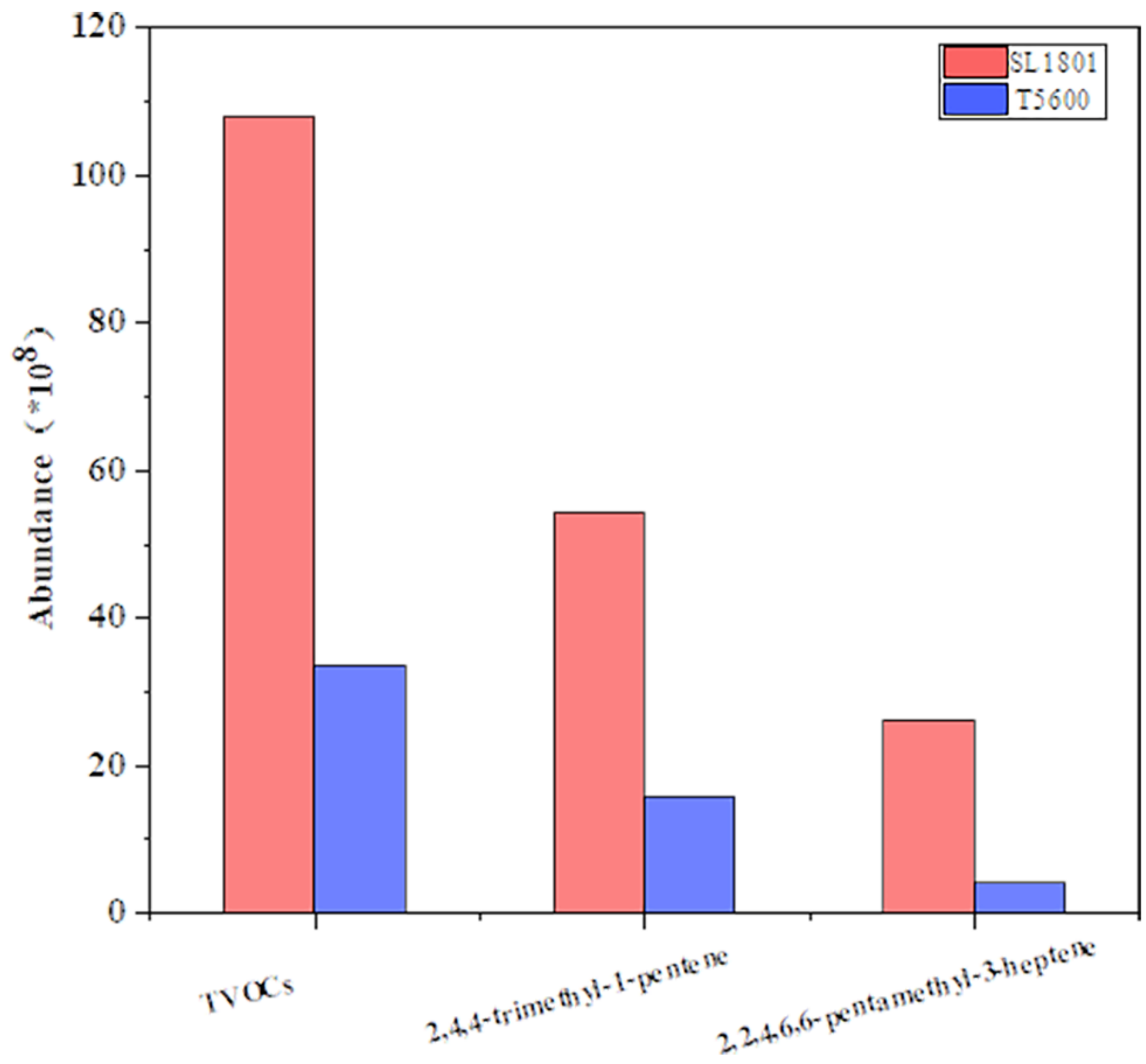

Figure 4

The abundance of VOCs in resin SL1801 and resins T5600 


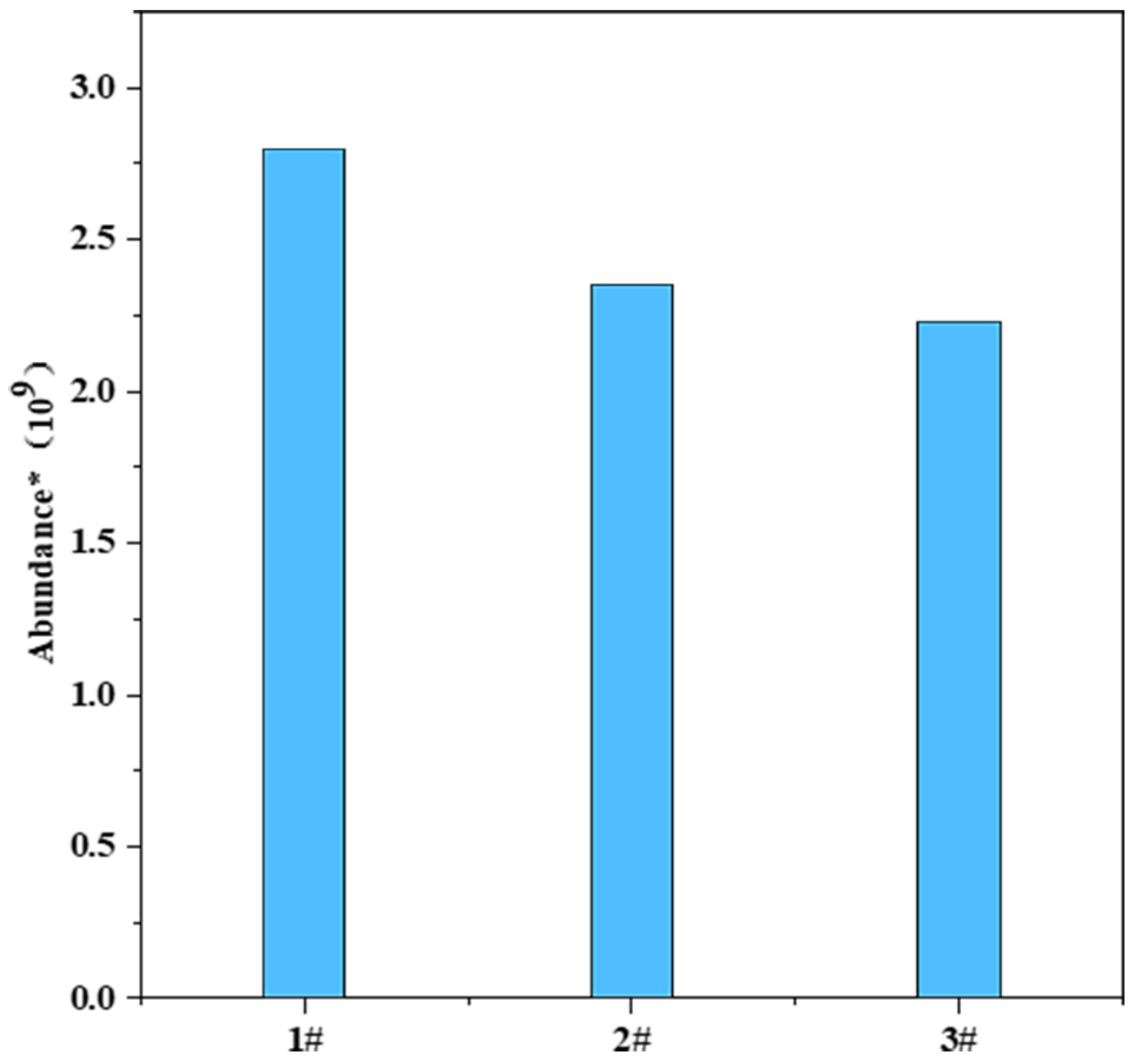

Figure 5

Results of the abundance of TVOCs after formulation changing

\section{Supplementary Files}

This is a list of supplementary files associated with this preprint. Click to download.

- Supplementary.docx 